\title{
Numerical Solution of a 3-D Advection-Dispersion Model for Dissolved Oxygen Distribution in Facultative Ponds
}

\author{
Sunarsih $^{1,2, *}$, Dwi P. Sasongko ${ }^{3}$, Sutrisno $^{1}$ \\ ${ }^{1}$ Department of Mathematics Faculty of Science and Mathematics, Diponegoro University,Semarang - Indonesia \\ ${ }^{2}$ School of Postgraduate Studies - Doctorate Program of Environmental Science, Diponegoro Univers ity,Semarang - Indonesia \\ ${ }^{3}$ Department of Physics Faculty of Science and Mathematics, Diponegoro University, Semarang -Indonesia
}

\begin{abstract}
This paper describes a mathematical model for the dissolved oxygen distribution in the plane of a facultative pond with a certain depth. The purpose of this paper is to determine the variation of dissolved oxygen concentration in facultative ponds. The 3-dimensional advectiondiffusion equation is solved using the finite difference method Forward Time Central Space (FTCS). Numerical results show that the aerator greatly affects the occurrence of oxygen concentration variations in the facultative pond in the certain depth. The concentration of dissolved oxygen decreases as the depth of the pond increases.
\end{abstract}

\section{Introduction}

Dissolved oxygen (DO) is one of the indicators of water quality. This is because dissolved oxygen plays a role in the oxidation process and reduction of organic and inorganic materials. In aerobic conditions, the role of oxygen is to oxidize organic and inorganic materials. Under anaerobic conditions, the resulting oxygen reduces the chemical compounds to be simpler in the form of nutrients and gases. This oxidation and reduction process that makes dissolved oxygen have an important role in reducing pollution load in waters either naturally or artificially [1].

The main source of oxygen in waters comes from a diffusion process of free air and products photosynthetic of organisms living in these waters. In the surface layer, high oxygen levels due to the diffusion process between water with free air and the process of photosynthesis. Then the oxygen level will decrease along with the increase of water depth. This is because the process of photosynthesis is reduced and oxygen levels are widely used for respiration and oxidation of organic and inorganic materials. Hence there is variation in the dissolved oxygen distribution in waters with different depths [2].

The process of reducing pollution loads in waters commonly used in Indonesia is the facultative pond system. The pond system is a process of wastewater treatment in a shallow pond with long residence time and using aeration process. Aeration is the giving of air into the water to increase the oxygen content by emitting water or passing air bubbles into the water so that the dissolved oxygen in the water is higher [3].
The aeration process in the facultative pond system, of course, will increase the variation of dissolved oxygen dissemination occurring in waters. Context of movement in facultative ponds can be divided into 2, namely advection and dispersion. Advection is a mechanism that moves a substance or matter from one position to another in space, or in other words refers to mass transfer by fluid speed [4]. Dispersions relate to fine insoluble or only slightly soluble particles distributed throughout a continuous medium [5]. Given the horizontal and vertical gradient of the pollutants in the pond room, the transport pollutant phenomenon with this advection and dispersion mechanism can be illustrated in 3-D model. This 3-D advection-diffusion mathematical model is represented by using partial differential equations.

Various studies have been conducted relate to advection-dispersion mechanisms with analytical and numerical solutions, that is [6] comparing several finite difference methods as FTCS, Upstream, Dufort Frankel and Crank Nicolson to solve one dimensional advectiondispersion equations. [7] gives 3 numerical methods for solving 2 advection-diffusion problems with initial conditions and specific boundary conditions. [8] provides examples of numerical solutions of advectiondispersion equations 3-dimensional using finite difference methods FTCS (Forward Time Central Space) with different initial values and boundary conditions. [9] develops and compares several different numerical techniques to solve a three dimensional advectiondiffusion equation.

Research has also been carried out by authors in the waste stabilization ponds, that is [10-11] solving the Chemical Oxygen Demand (COD) concentration 
deployment model on one side of the waste stabilization pool (1-D) and on a plane (2-D) with based on advection-diffusion mechanisms using finite difference Dufort Frankel and [12] solving advection-diffusion model of Biological Oxygen Demand (BOD) concentration of 2-dimension using finite difference method.

Based on the description, this article provides a numerical solution of the 3-Dimensional advectiondispersion model of the variation distribution dissolved oxygen (DO) using finite difference methods FTCS scheme.

\section{Materials and Methods}

\subsection{Distribution Model of Dissolved Oxygen (DO) of Advection-Dispersion}

The development of the dissolved oxygen mathematical equation with 1 -way flow considering the depth can be described as follows [8]:

$$
\frac{\partial C}{\partial t}=-\frac{\partial(u C)}{\partial x}+D_{m x} \frac{\partial^{2} C}{\partial x^{2}}+D_{m y} \frac{\partial^{2} C}{\partial y^{2}}+D_{m z} \frac{\partial^{2} C}{\partial z^{2}}
$$

\subsection{Finite Difference Method Forward Time Central Space (FTCS)}

In general, the basis of the finite difference method is to obtain the value of the variable as a function of space in the time step $t+\Delta t$ with the spatial distribution in the time step to $t$ is known. The Forward Time Central Space Scheme in question is derivative approximation of time by using forward finite difference and space by using central finite difference. The derivative approximation by using finite difference FTCS is [7]:

$$
\begin{gathered}
\frac{\partial C}{\partial t}(i \Delta x, j \Delta y, k \Delta z, t \Delta t)=\frac{C_{i, j, k}^{t+1}-C_{i, j, k}^{t}}{\Delta t}-\mathrm{O}(\Delta t) \\
\frac{\partial C}{\partial x}(i \Delta x, j \Delta y, k \Delta z, t \Delta t)=\frac{C_{i+1, j, k}^{t}-C_{i-1, j, k}^{t}}{2 \Delta x}-\mathrm{O}\left(\Delta x^{2}\right) \\
\frac{\partial^{2} C}{\partial x^{2}}(i \Delta x, j \Delta y, k \Delta z, t \Delta t)=\frac{C_{i+1, j, k}^{t}-2 C_{i, j, k}^{t}+C_{i-1, j, k}^{t}}{\Delta x^{2}}+\mathrm{O}\left(\Delta x^{2}\right) \\
\frac{\partial^{2} C}{\partial y^{2}}(i \Delta x, j \Delta y, k \Delta z, t \Delta t)=\frac{C_{i, j+1, k}^{t}-2 C_{i, j, k}^{t}+C_{i, j-1, k}^{t}}{\Delta y^{2}}+\mathrm{O}\left(\Delta y^{2}\right) \\
\frac{\partial^{2} C}{\partial z^{2}}(i \Delta x, j \Delta y, k \Delta z, t \Delta t)=\frac{C_{i, j, k+1}^{t}-2 C_{i, j, k}^{t}+C_{i, j, k-1}^{t}}{\Delta z^{2}}+\mathrm{O}\left(\Delta z^{2}\right)
\end{gathered}
$$

This research is a case study by assuming dissolved oxygen is present in a plane with a certain depth. The points on a plane are given in the same horizontal and vertical direction, but with 3 different depths. Thus will be obtained 3 fields with 9 different points. The pond discretization regarding this case study is shown in Figure 1.

\section{Results and Discussions}

Equation (1) would be discrete form using a finite difference method FTCS scheme by substituting equation (2) - (6) to equation (1), so the following result are obtained:

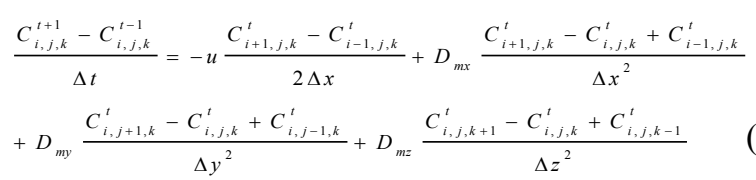

With algebraic manipulation, equation (7) could be written as follows:

$$
\begin{aligned}
& C_{i, j, k}^{t+1}=C_{i-1, j, k}^{t}\left\lceil\frac{u \Delta t}{2 \Delta x}+\frac{D_{m x} \Delta t}{\Delta x^{2}}\right]+C_{i, j, k}^{t}\left[1-2 \frac{D_{m x} \Delta t}{\Delta x^{2}}-2 \frac{D_{m y} \Delta t}{\Delta y^{2}}-2 \frac{D_{m z} \Delta t}{\Delta z^{2}}\right] \\
& +C_{i, j+1, k}^{t}\left\lfloor\left[\frac{D_{m y} \Delta t}{\Delta y^{2}}\right\rfloor+C_{i, j-1, k}^{t}\left\lceil\frac{D_{m y} \Delta t}{\Delta y^{2}}\right\rfloor+C_{i+1, j, k}^{t}\left\lfloor-\frac{u \Delta t}{2 \Delta x}+\frac{D_{m x} \Delta t}{\Delta x^{2}}\right]\right. \\
& +C_{i, j, k+1}^{t}\left[\frac{D_{m z} \Delta t}{\Delta z^{2}}\right]++C_{i, j, k-1}^{t}\left\lfloor\frac{D_{m z} \Delta t}{\Delta z^{2}}\right]
\end{aligned}
$$

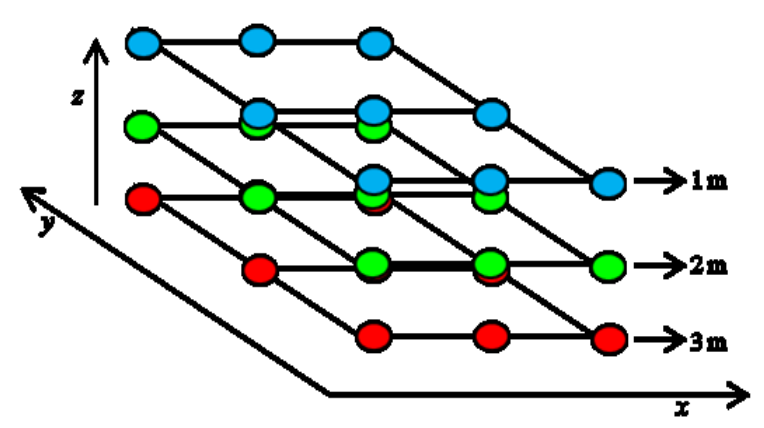

Fig. 1. Pond Discretization Based on Depth Level

Using this equation (8) we would calculate the value of $C_{i, j}^{t+1}$ using the initial values and bounds in each plane up to the desired iteration. Because the calculation process was very long, it would be solved with the help of MATLAB.

To solve the equation, given the values of the diffusion coefficient parameter $D_{m x}=8.23 \times 10^{-5} \mathrm{~m}^{2} / \mathrm{s}$, $D_{m y}=8.23 \times 10^{-5} \mathrm{~m}^{2} / \mathrm{s}, D_{m z}=8.23 \times 10^{-5} \mathrm{~m}^{2} / \mathrm{s}$, flow velocity $u=1.09 \mathrm{~m} / \mathrm{s}$, flow length $t=24$ hour , depth $h=4 \mathrm{~m}$. Then given grids with sizes $\Delta x 1=11, \Delta x 2=27.5, \Delta y 1=10$, $\Delta y 2=25, \Delta h=1$ and $\Delta t=1$. Determination of the grid is adjusted to the size of the pond, which is the length of the pond $=77$ meters and the width of the pond 70 meters.

The simulated results of dissolved oxygen distribution in the pond plane with a depth of 1 meter at time $t+1$ can be shown in Figure 2 .

Figure 2 shows that the high dissolved oxygen concentration in the middle of the pond is slowly spreading and decreasing at the edges of the pond. This is thought to be due to an aerator in the middle of the pond. 


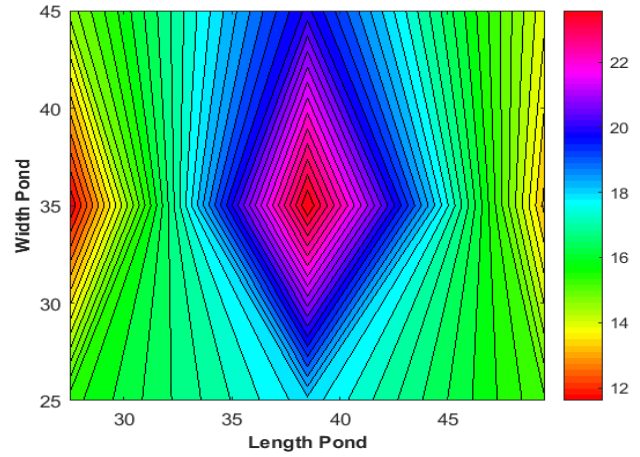

Fig. 2. Distribution DO on Pond Plane with Depth $1 \mathrm{~m}$

The simulation results of dissolved oxygen distribution in the plane of pond with a depth of 2 meters at time $t+1$ can be shown in Figure 3 .

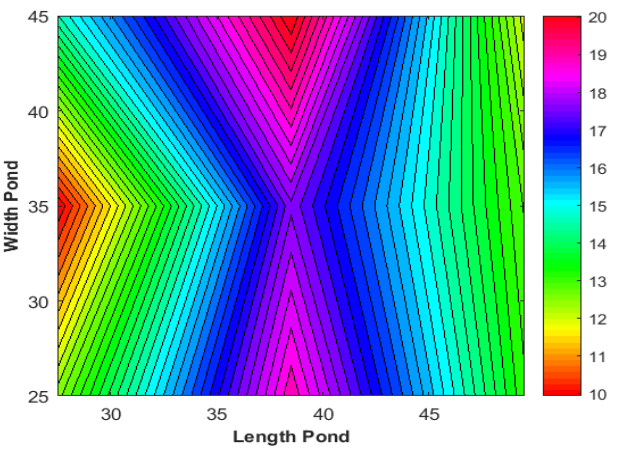

Fig. 3. Distribution DO on Pond Plane with Depth $2 \mathrm{~m}$

Figure 3 states that the initial high concentration of dissolved oxygen on the upper edge of the center of the pond slowly decreases until it reaches the center of the pond. But it increases back to the bottom edge of the pond.

Based on the observations of Figures 2 and 3, it is seen that dissolved oxygen distribution tends to differ in the middle of the pond. The dominant spread which occurs in the middle of the pond as if moving towards the top and bottom edge of the pond. The dissolved oxygen distribution that occurs on the right and left edge of the pool tends to look the same. This indicates that the aerator in the center of the pond does not affect the dissolved oxygen distribution at a depth of 2 meters.

The simulated results of the dissolved oxygen distribution in the pond plane with a depth of 3 meters at time $\mathrm{t}+1$ can be shown in Figure 4 .

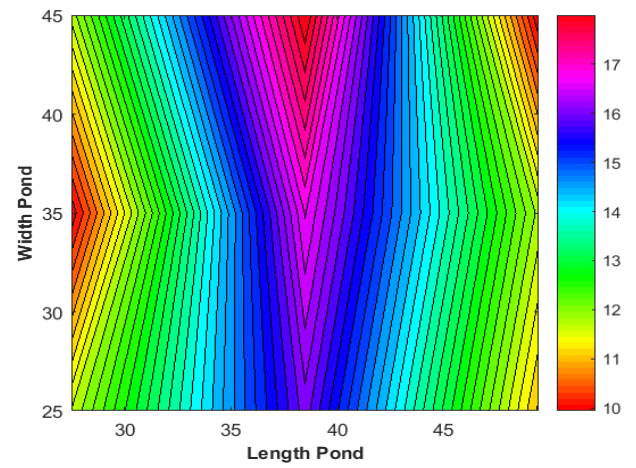

Fig. 4. Distribution DO on Pond Plane with Depth $3 \mathrm{~m}$
Figure 4 states that the previously high concentration of dissolved oxygen at the upper edge of the center of the pond slowly decreases to the bottom edge of the pond. However, the dissolved oxygen concentration at the upper edge of the center of the pond at a depth of 3 meters is lower than at a depth of 2 meters.

Based on the observations of Figures 2 through 4, it appears that the dissolved oxygen concentration decreases with increasing depth of the pond. In addition, dissolved oxygen distribution also looks different. This indicates that there is a variation in the concentration of dissolved oxygen in the facultative pond, especially at a certain depth.

The variation in the dissolved oxygen distribution is more clearly seen in the 3-dimensional image as shown in Figure 5.

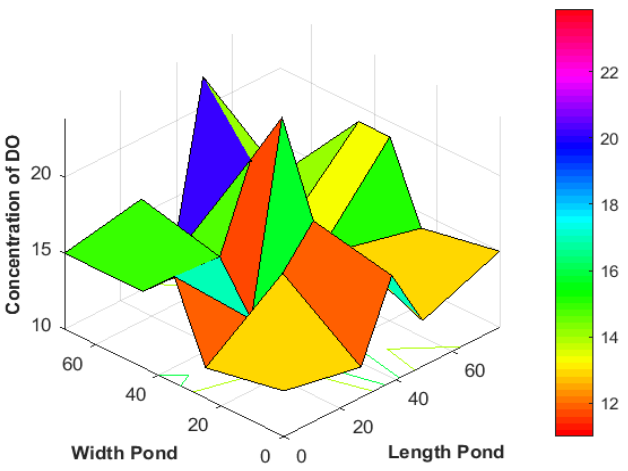

(a)

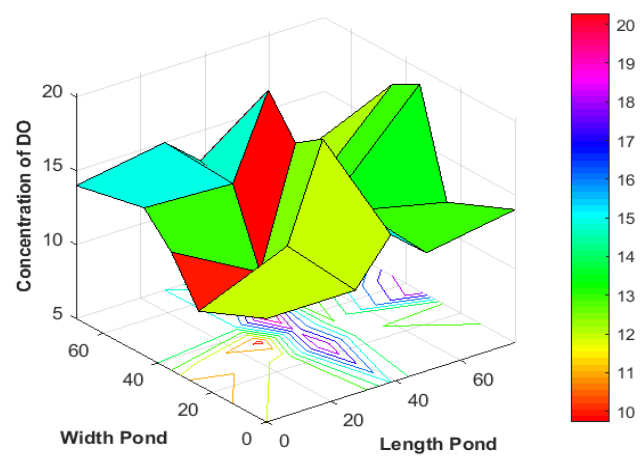

(b)

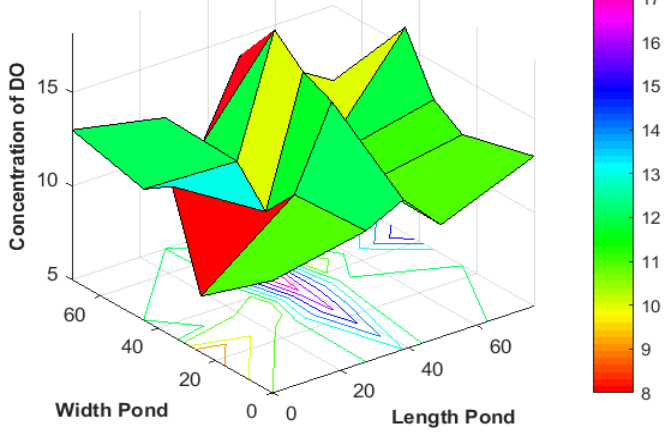

(c)

Fig. 5. Variation of Dissolved Oxygen Distribution (a) Depth of 1 meter (b) 2 meters (c) 3 meters 


\section{Conclusions}

Based on the results and discussion, it can be concluded that there is a variation in the concentration of dissolved oxygen in the facultative pond, especially at a certain depth. The dissolved oxygen concentration decreases based on the depth of the pond and its distribution differs only in the middle of the pond. This shows that the aerator greatly affects the occurrence of variations in oxygen concentration. However, this aerator can function optimally on the surface of the pond to a depth of 1 meter. At a depth of more than 1 meter, the process of photosynthesis occurs less than the maximum so that the aerator also can not help increase the concentration of oxygen with the maximum as well.

\section{References}

1. D. A. Fuchs, An Institutional Basis for Environmental Stewardship (Kluwer Academic Publishers, London, 2003)
2. F. R. Spellman, Handbook of Water and Wastewater Treatment Plant Operations (CRC Press Taylor \& Francis Group, 2014)

3. A. Boyce, Introduction to Environmental Technology (John Wiley \& Sons Inc, New York, 1997)

4. A. James, An Introduction to Water Quality Modelling (John Wiley \& Sons Inc, England)

5. E. Kissa, Dispersions Characterization, Testing, and Measurement (Marcel Dekker Inc, New York, 1999)

6. H. S. Najafi, H. Hajinezhad, Appl. Math. Sci. 2, 2611-2618 (2008)

7. A. R. Appadu, J. K. Djoko, H. H. Gidey, Appl. Math. Comp. 272, 629-647 (2016)

8. M. Thongmoon, R. McKibbin, R. Tangmanee, Thai J. Math. 5, 91-108 (2007)

9. M. Dehghan, Appl. Math. Comp. 150, 5-19 (2004)

10. Sunarsih, D. P. Sasongko, Sutrisno, Adv. Sci. Lett. 23, 2383-2385 (2017)

11. Sunarsih, Farikhin, H. Rya, Anies, Adv. Sci. Lett. 23, 2273-2276 (2017) 